\title{
Laser Vestibuloplasty for Peri-implant Gingiva Implementation in the Atrophic Mandible of a Medically Compromised Patient
}

\author{
Domenico De Falco ${ }^{1}$, Daniela Di Venere ${ }^{1}$, Gianfranco Favia ${ }^{1}$ \\ 1. Dentistry, University of Bari Aldo Moro, Bari, ITA
}

Corresponding author: Domenico De Falco, defalcodomenico@ymail.com

\begin{abstract}
Despite the good clinical outcomes of the conventional technique of vestibulopasty performed with a scalpel, patients frequently perceive pain and discomfort after surgery. Diode laser use in oral surgery is, instead, well tolerated as it is mini-invasive and with a very low occurrence of post-surgical complications. In addition, the lack of bleeding during surgery and the reduced/absent post-surgical edema makes diode laser surgery the most suitable for medically compromised patients. We report a case of vestibuloplasty performed by diode laser in a patient on therapy with warfarin and without drug discontinuation.
\end{abstract}

Categories: Dentistry

Keywords: vestibuloplasty, perimplant gingiva, diode laser, oral surgery

\section{Introduction}

It is generally accepted that the long-lasting duration of dental implants is strictly related to the quality and quantity of the keratinized gingiva [1]. Prosthetic rehabilitation of atrophic mandible by implant-retained overdenture is frequently associated with a reduced or poor quality adherent gingiva, thus needing its implementation. Among all techniques reported in the literature, the conventional technique of vestibuloplasty performed with a scalpel is surely the most used, although characterized by pain and discomfort perceived by patients. Above all, it is related to post-surgical edema and difficulties in swallowing, chewing, and speaking [2-6]. Such complications could become more evident in medically compromised patients (e.g. on anticoagulant therapy) [7]. The use of a laser with good surgical capabilities (especially contextual cut and coagulation) may surely improve clinical outcomes in patients needing vestibuloplasty $[5,6,8]$. We report the case of a patient who underwent vestibuloplasty by diode laser to implement the keratinized gingiva around dental implants in an atrophic mandible; the patient was in therapy with warfarin and without drug discontinuation.

Received 03/03/2020 Review began 03/06/2020 Review ended 03/17/2020 Published 03/21/2020

(c) Copyright 2020

De Falco et al. This is an open access article distributed under the terms of the Creative Commons Attribution License CC-BY 4.0., which permits unrestricted use, distribution, and reproduction in any medium, provided the original author and source are credited.

\section{Case Presentation}

The patient was a 75-year-old female who received four implants in the mandible for prosthetic rehabilitation by overdenture. She was in therapy with warfarin for chronic atrial fibrillation. Three months after the implant insertion, a clinical examination revealed the poor quality and quantity of keratinized gingiva around the fixtures. More precisely, it revealed the proximity of caruncula sublingualis and the absence of an inadequate deepening of both buccal and lingual vestibula of the mandible limited the prosthetic space and causing instability of the peri-implant gingiva (Figures $1 a-1 b$ ). The patient was treated by diode laser surgery (wavelength $980 \pm 10 \mathrm{~nm}$; continuous wave, output energy $1.5 \mathrm{~W}$ ) without warfarin discontinuation; healing caps were removed and the implant was re-covered with gingiva using stitches, and vestibuloplasty was performed (by using a diode laser) on both aspects of the mandible with contextual lingual frenulotomy (Figure 1c). No bleeding was observed during surgery and stitches were unnecessary; no post-surgical complications occurred. After 15 days, a complete resolution of all wounds was observable with an evident increase of the available prosthetic space (Figure 1d). 


\section{Cureus}
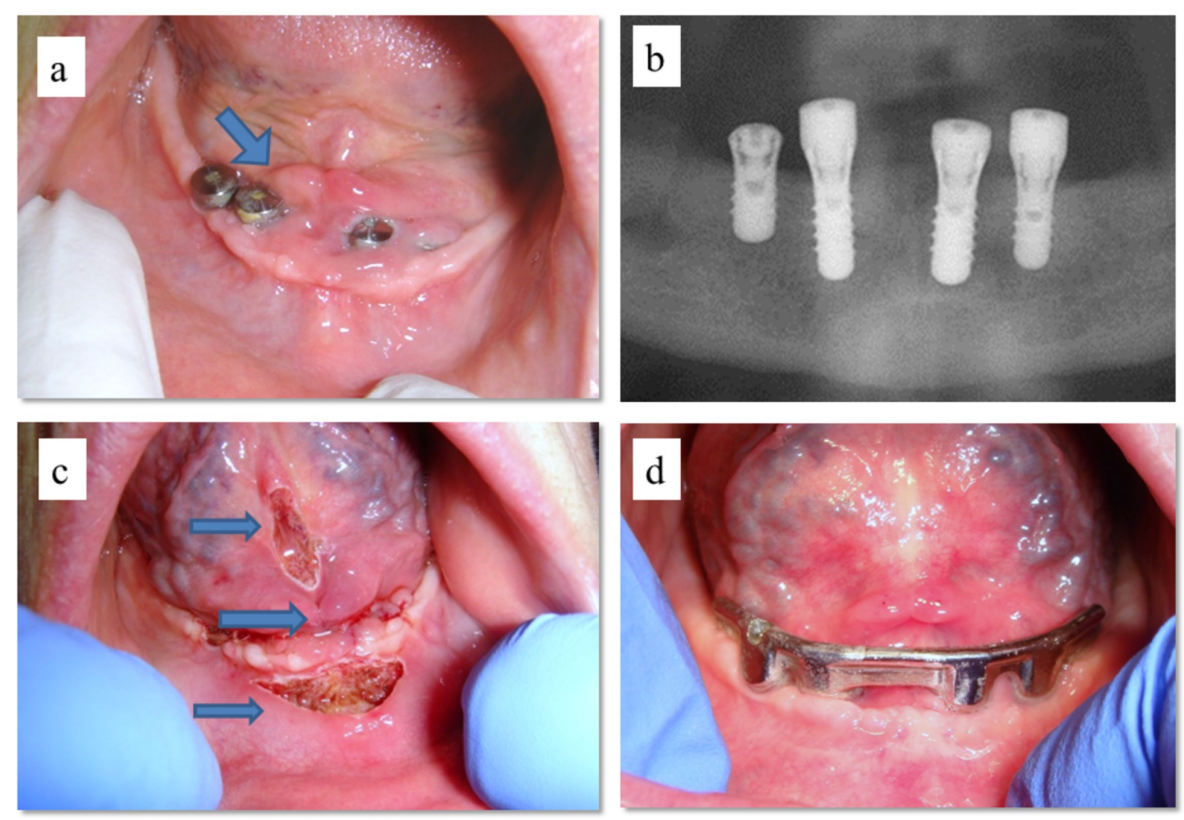

\section{FIGURE 1: Clinical appearance of soft tissues around the dental implants in the atrophic mandible of the patient in anticoagulant therapy three months after insertion}

(a,b); caruncula sublingualis (arrow) appeared in proximity of the gingiva, resulting un-adherent and mobile around fixtures; diode laser surgery of both lingual and buccal vestibula along with tongue frenulotomy (arrows) (c); clinical appearance after 15 days showing implementation of the peri-implant keratinized gingiva, with creation of a sufficient prosthetic space for the following rehabilitation (d).

\section{Discussion}

Anticoagulant therapies are usually modified/suspended in patients needing oral surgery procedures to prevent both intra- and post-operative bleeding [7,9]. The generally accepted advantages of diode laser use in oral surgery are the decreased need of anaesthesia, the lack of intra-operatory bleeding, the reduction of post-operative oedema, unnecessary stitches, and the acceleration of mucosa healing [8]. For such reasons, laser therapy represents a safe and predictable procedure for several surgical and not-surgical treatments in the oral cavity, e.g. periodontal decontamination, non-surgical drug-related gingival overgrowth treatment, surgical removal of benign proliferating lesions as well as of oral mucosa malignancies [10-14]. The use of diode laser for vestibuloplasty, in patients on anticoagulant therapy, is associated with a shorter operating time and fewer postoperative complications compared to conventional scalpel surgery including the unnecessary drug discontinuation $[5,6]$.

\section{Conclusions}

Among all lasers with proven surgical capabilities, the diode laser is widely used for the surgical excision of proliferating lesions and photocoagulation of small and large venous malformations in the oral cavity. Although vestibuloplasty may represent an invasive procedure in medically compromised patients, especially during possible intra-operative bleeding and the following post-surgical edema of the floor of the mouth, diode laser use allows to simplify such procedure in terms of operating time, invasiveness, really reducing pain and discomfort, while at the same time achieving excellent clinical outcomes.

\section{Additional Information \\ Disclosures}

Human subjects: Consent was obtained by all participants in this study. Conflicts of interest: In compliance with the ICMJE uniform disclosure form, all authors declare the following: Payment/services info: All authors have declared that no financial support was received from any organization for the submitted work. Financial relationships: All authors have declared that they have no financial relationships at present or within the previous three years with any organizations that might have an interest in the submitted work. Other relationships: All authors have declared that there are no other relationships or activities that could appear to have influenced the submitted work. 


\section{References}

1. Lin GH, Chan HL, Wang HL: The significance of keratinized mucosa on implant health: a systematic review . J Periodontol. 2013, 84:1755-67. 10.1902/jop.2013.120688

2. Lim HC, An SC, Lee DW: A retrospective comparison of three modalities for vestibuloplasty in the posterior mandible: apically positioned flap only vs. free gingival graft vs. collagen matrix. Clin Oral Investig. 2018, 22:2121-2128. 10.1007/s00784-017-2320-y

3. Schmitt CM, Moest T, Lutz R, Wehrhan F, Neukam FW, Schlegel KA: Long-term outcomes after vestibuloplasty with a porcine collagen matrix (Mucograft ${ }^{\circledR}$ ) versus the free gingival graft: a comparative prospective clinical trial. Clin Oral Implants Res. 2016, 27:e125-e133. 10.1111/clr.12575

4. Markose G, Graham RM, Woodwards RTM, Nasry H, Thomson EF: Modified tie-over technique for lingual sulcoplasty (vestibuloplasty). Br J Oral Maxillofac Surg. 2019, 57:90-92. 10.1016/j.bjoms.2018.05.006

5. Hanna R, Amaroli A, Signore A, Benedicenti S: Utilization of carbon dioxide laser therapy in the management of denture-induced hyperplasia and vestibuloplasty in a medically compromised patient: a case report. Int J Prosthodont. 2019, 32:211-213. 10.11607/ijp.6046

6. Kalakonda B, Farista S, Koppolu P, et al.: Evaluation of patient perceptions after vestibuloplasty procedure: a comparison of diode laser and scalpel techniques. J Clin Diagn Res. 2016, 10:96-100.

10.7860/JCDR/2016/17623.7820

7. António N, Castro G, Ramos D, Machado A, Gonçalves L, Macedo T, Providência LA: The debate concerning oral anticoagulation: whether to suspend oral anticoagulants during dental treatment. Rev Port Cardiol. 2008, 27:531-44.

8. Derikvand N, Chinipardaz Z, Ghasemi S, Chiniforush N: The versatility of $980 \mathrm{~nm}$ diode laser in dentistry: a case series. J Lasers Med Sci. 2016, 7:205-208. 10.15171/jlms.2016.36

9. Isola G, Matarese G, Cordasco G, Rotondo F, Crupi A, Ramaglia L: Anticoagulant therapy in patients undergoing dental interventions: a critical review of the literature and current perspectives. Minerva Stomatol. 2015, 64:21-46.

10. Limongelli L, Tempesta A, De Caro A, Maiorano E, Angelelli G, Capodiferro S, Favia G: Diode laser photocoagulation of intraoral and perioral venous malformations after tridimensional staging by high definition ultrasonography. Photobiomodul Photomed Laser Surg. 2019, 37:722-728. 10.1089/photob.2019.4635

11. Bacci C, Sacchetto L, Zanette G, Sivolella S: Diode laser to treat small oral vascular malformations: a prospective case series study. Lasers Surg Med. 2018, 50:111-116. 10.1002/1sm.22737

12. Capodiferro S, Limongelli L, Tempesta A, Maiorano E, Favia G: Diode laser treatment of venous lake of the lip. Clin Case Rep. 2018, 6:1923-1924. 10.1002/ccr3.1735

13. Capodiferro S, Tempesta A, Limongelli L, Maiorano E, Benedicenti S, Favia G: Nonsurgical periodontal treatment by erbium:Yag laser promotes regression of gingival overgrowth in patient taking cyclosporine A: a case report. Photobiomodul Photomed Laser Surg. 2019, 37:53-56. 10.1089/photob.2018.4478

14. Limongelli L, Capodiferro S, Tempesta A, et al.: Early tongue carcinomas (clinical stage I and II): echoguided three-dimensional diode laser mini-invasive surgery with evaluation of histological prognostic parameters. A study of 85 cases with prolonged follow-up. Lasers Med Sci. 2019, 35:751-758. 10.1007/s10103-019-02932-z 